\title{
Article \\ Laser Grinding of Single-Crystal Silicon Wafer for Surface Finishing and Electrical Properties
}

\author{
Xinxin $\mathrm{Li}^{1,+}$, Yimeng Wang ${ }^{1,+}$ (D) and Yingchun Guan ${ }^{1,2,3,4, *}$ \\ 1 School of Mechanical Engineering and Automation, Beihang University, 37 Xueyuan Road, \\ Beijing 100083, China; lixx0912@buaa.edu.cn (X.L.); ymwang1007@buaa.edu.cn (Y.W.) \\ 2 National Engineering Laboratory of Additive Manufacturing for Large Metallic Components, \\ Beihang University, 37 Xueyuan Road, Beijing 100083, China \\ 3 International Research Institute for Multidisciplinary Science, Beihang University, 37 Xueyuan Road, \\ Beijing 100083, China \\ 4 Ningbo Innovation Research Institute, Beihang University, Beilun District, Ningbo 315800, China \\ * Correspondence: guanyingchun@buaa.edu.cn \\ + The two authors contributed equally to this work.
}

Citation: Li, X.; Wang, Y.; Guan, Y. Laser Grinding of Single-Crystal Silicon Wafer for Surface Finishing and Electrical Properties.

Micromachines 2021, 12, 262. https:// doi.org/10.3390/mi12030262

Academic Editor: Rafael J. Taboryski

Received: 29 January 2021

Accepted: 2 March 2021

Published: 4 March 2021

Publisher's Note: MDPI stays neutral with regard to jurisdictional claims in published maps and institutional affiliations.

Copyright: (c) 2021 by the authors. Licensee MDPI, Basel, Switzerland. This article is an open access article distributed under the terms and conditions of the Creative Commons Attribution (CC BY) license (https:// creativecommons.org/licenses/by/ $4.0 /)$.

\begin{abstract}
In this paper, we first report the laser grinding method for a single-crystal silicon wafer machined by diamond sawing. 3D laser scanning confocal microscope (LSCM), X-ray diffraction (XRD), scanning electron microscope (SEM), X-ray photoelectron spectroscopy (XPS), laser microRaman spectroscopy were utilized to characterize the surface quality of laser-grinded Si. Results show that $\mathrm{SiO}_{2}$ layer derived from mechanical machining process has been efficiently removed after laser grinding. Surface roughness Ra has been reduced from original $400 \mathrm{~nm}$ to $75 \mathrm{~nm}$. No obvious damages such as micro-cracks or micro-holes have been observed at the laser-grinded surface. In addition, laser grinding causes little effect on the resistivity of single-crystal silicon wafer. The insights obtained in this study provide a facile method for laser grinding silicon wafer to realize highly efficient grinding on demand.
\end{abstract}

Keywords: laser grinding; nanosecond laser; single-crystal silicon wafer; surface finishing; resistivity

\section{Introduction}

Single-crystal silicon wafer has been widely used in semiconductor applications including computer systems, telecommunications equipment, automobiles, consumer electronics, automation and control systems, analytical and defense systems [1]. High-quality silicon wafers without damages are essential for these applications. In semiconductor industry, silicon wafer is usually produced by slicing, edge profiling, lapping, grinding, etching, grinding, and cleaning processes [2,3]. Damages such as amorphous layers, dislocations, and microcracks, can be produced at the surface of silicon wafers during mechanical machining processes $[4,5]$. These damages will reduce performance and lifetime of the wafers [6]. Although the post processes such as chemo-mechanical polishing (CMP) process [7] and etched-wafer fine grinding [8] can reduce damaged layers, it increases the total costs significantly.

Laser surface microprocessing has been an emerging technology, which has many advantages rather than traditional methods including non-contact, environmentally friendly, and high flexibility $[9,10]$. Till now, laser microprocessing such as laser recovery, laser microtexturing, laser annealing, and laser drilling have been successfully used for semiconductor materials. Yan et al. reported that the amorphous layers transformed to single-crystal silicon and dislocations and microcracks were completely eliminated by using nanosecondpulsed laser. Moreover, the roughness of the surface was reduced from RMS $=12 \mathrm{~nm}$ to $8 \mathrm{~nm}$ after laser recovery [4,11-13]. Gupta et al. have used nanosecond pulse laser annealing to successfully demonstrate the phase evolution of single-crystal silicon wafer 
with different pulse widths and laser fluences [14]. Mahdieh et al. have reported that the roughness of amorphous silicon wafer was reduced from RMS $9 \mathrm{~nm}$ to $0.5 \mathrm{~nm}$ after nanosecond laser annealing [15]. Wang et al. successful obtained nanostructure on amorphous thin silicon film surface using femtosecond pulse laser and found the absorptance of $\mathrm{Si}$ thin film increased after laser irradiation [16]. Zheng et al. produced regular arrays of sub-micron bumps on single-crystal silicon wafer by using a continuous wave fiber laser [17]. Jiao et al. generated holes on single-crystal silicon wafer using femtosecond laser and the spatter area decreased and drilling efficiency increased with substrate temperature increase [18]. However, there is little discussion in the literature using laser grinding method to improve the surface quality of single-crystal silicon wafer.

The objective of this study is to investigate the effect of nanosecond pulsed laser grinding on surface improvement of single-crystal silicon wafer. The influence of laser grinding on the surface modification, microstructure, and resistivity of single-crystal silicon wafer was studied. Roughness reduction of single-crystal silicon wafer before and after laser grinding were evaluated. Moreover, the evolution of chemical composition, crystallinity and resistivity of single-crystal silicon wafer surface were discussed during laser grinding.

\section{Materials and Methods}

Single-crystal silicon wafer machined by diamond sawing were used, with the thickness of $525 \mu \mathrm{m}$, orientation of $\langle 100\rangle$, with the boron doping concentration of $10^{16} / \mathrm{cm}^{3}$, with the diameter of 4 inch.

The $1064 \mathrm{~nm}$ wavelength nanosecond pulse laser with a full laser power of $100 \mathrm{~W}$ at the $100 \%$ set point and a laser pulse width of $220 \mathrm{~ns}$ is employed to irradiated singlecrystal silicon wafer. Figure 1 illustrates the schematic for the experimental setup of laser grinding silicon wafer. In order to focus and scan the laser beam in the horizontal and vertical directions, a two-mirror galvanometric scanner with an F-theta objective lens is used. The focal beam diameter of $35 \mu \mathrm{m}$ can be achieved and the beam has a Gaussian energy distribution. Formation of typical morphologies and microstructure is the result of synergistic combination between laser power (pulse energy) and scanning speed. During our experimental study, we have actually conducted DoE analyses and particularly selected laser power as $50 \%, 55 \%, 60 \%, 65 \%, 70 \%, 75 \%, 80 \%, 85 \%$; scanning speed as $1500 \mathrm{~mm} / \mathrm{s}$, $2000 \mathrm{~mm} / \mathrm{s}, 2500 \mathrm{~mm} / \mathrm{s}, 3000 \mathrm{~mm} / \mathrm{s}, 3500 \mathrm{~mm} / \mathrm{s}, 4000 \mathrm{~mm} / \mathrm{s}, 4500 \mathrm{~mm} / \mathrm{s}, 5000 \mathrm{~mm} / \mathrm{s}$; scanning times as $1,2,3,4$. According to $\mathrm{L}_{64}\left(8^{9}\right)$ the orthogonal table, we have totally carried out 64 process parameters. The optimum process condition for surface quality and properties according to the orthogonal experiment is reported. When laser power is set to $65 \%$, scanning speed of the laser beam is $3000 \mathrm{~mm} / \mathrm{s}$, laser frequency is $100 \mathrm{kHz}$, scanning interval is $20 \mu \mathrm{m}$. The laser intensity was $6.75 \times 10^{6} \mathrm{~W} / \mathrm{cm}^{2}$. The grinded process experiments are performed in an Ar shields environment.

To examine the surface topography, the sample surface was observed using a 3D laser scanning confocal microscope (LSCM, VK-X100, KEYENCE, Osaka, Japan) and scanning electron microscope (SEM, GEMINISEM 500, ZEISS, Oberkochen, Germany) equipped with an energy dispersive spectrometer (EDS). The surface Ra are evaluated by surface profilometers (MahrSurf M 300 C, Mahr, Göttingen, Germany). Phase composition of silicon wafer was determined by X-ray diffractometer (XRD, D/max2200PC, Rigaku, Tokyo, Japan). A laser micro-Raman spectrometer (inVia Reflex, Renishaw, Gloucestershire, UK) was used to examine the surface crystal structure. The laser wavelength of the spectrometer was $532 \mathrm{~nm}$. The room-temperature $I-V$ characteristic curves and resistivity of single-crystal silicon wafers were tested by four-probe method using an ZEM-3 system (Ulvac RIko, Chigasaki, Kanagawa, Japan) instrument to obtain the influence of laser irradiation on electrical properties of silicon wafer without the effect of probe position on the result. 


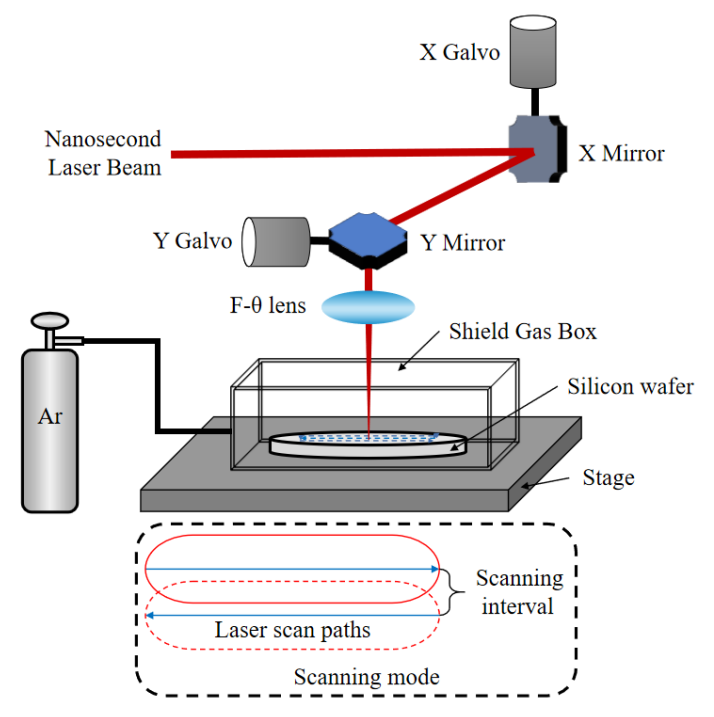

Figure 1. Schematic for experimental setup of laser grinding single-crystal silicon wafer.

\section{Result and Discussion}

\subsection{Effect of Laser Grinding on Surface Morphology}

The surfaces morphology of the as-revised and laser-grinded single-crystal silicon wafer samples are shown in Figure 2a. Ra is the arithmetic mean of the surface roughness profile; $\mathrm{Rz}$ is the height of the irregularities of the surface roughness profile at 10 points. The left half of Figure 2a shows the surface morphology of the as-received surface and surface roughness values $\mathrm{Ra}$ and $\mathrm{Rz}$ were $0.4 \mu \mathrm{m}$ and $2.47 \mu \mathrm{m}$, respectively. The original surface exhibits a rough appearance. Numerous small embossments and some grooves can be seen on the surface. This indicated that the smooth surface could not be obtained after mechanical sawing. The right half of Figure 2a shows the surface morphology of the lasergrinded surface. After laser grinding, surface roughness $\mathrm{Ra}$ and $\mathrm{Rz}$ value were reduced to $0.075 \mu \mathrm{m}$ and $0.34 \mu \mathrm{m}$, respectively. It was immediately apparent that following laser grinding there was a large improvement in surface quality, with the grinded regions being significantly smoother compared to the as-received surface. This phenomenon suggests that the embossment and groove are melted and incorporated during laser grinding.

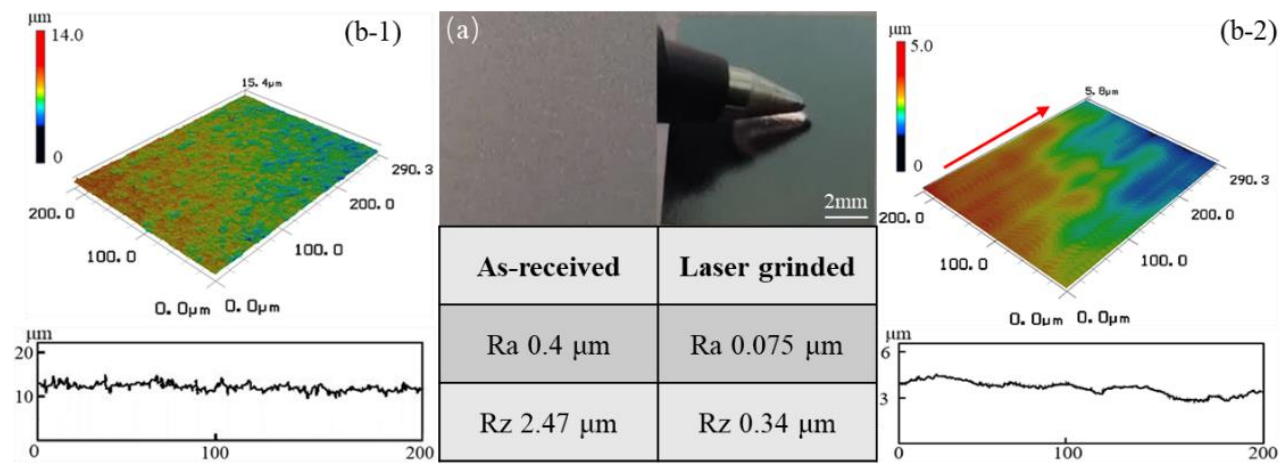

Figure 2. Surface topography: (a) as-received and laser-grinded surfaces at macro-scale; (b-1) 3D topographic image of as-received surface, (b-2) 3D topographic image of the laser-grinded surface.

The top images of Figure $2 b-1$ and Figure $2 b-2$ illustrate the three-dimensional (3D) surface topographies of the as-received surface and laser-grinded surface, respectively. The 3D profile of the samples within a measurement region of $200 \mu \mathrm{m} \times 290.3 \mu \mathrm{m}$ of the top surface. The red arrow in Figure $2 b-2$ represents the laser grinding direction. Abundant peaks are observed on the as-received surface, and, after laser grinding, the number peaks are reduced and the surface is smoothed. The maximum peak height is reduced from $14 \mu \mathrm{m}$ 
to $5 \mu \mathrm{m}$. However, ripples on the samples used in this work can be observed along the direction of the scan track of the laser. The bottom images of Figure 2b-1 and Figure 2b-2 are the two-dimensional (2D) surface profiles of the as-received surface and laser-grinded surface, respectively. The linear surface profiles of the samples, which have a length of $200 \mu \mathrm{m}$, are taken from lines perpendicular to the laser-grinding direction. The surface profiles of the as-received surface fluctuates between $9.21 \mu \mathrm{m}$ and $14.8 \mu \mathrm{m}$, whereas that of laser grinding fluctuates between $2.66 \mu \mathrm{m}$ and $4.8 \mu \mathrm{m}$.

The mechanism of laser grinding includes two steps, which are shown in Figure 3a,b. The first step is laser directly removal of scratches and oxides caused by sawing process. The laser beam with high energy density is absorbed by the surface oxide layer, which forms a rapidly expanding plasma and produces shock wave. The shock wave causes the pollutants to fragment and be removed [19]. While the next step is laser melting due to thermal accumulation. Figure $3 \mathrm{c}$ shows that the surface of silicon wafer melts during laser grinding. Molten silicon is redistributed in flow due to the simultaneous action of surface tension and Maragani effect [20].

(a)

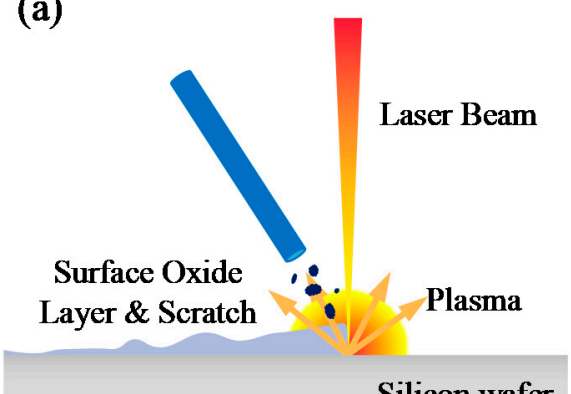

(b)

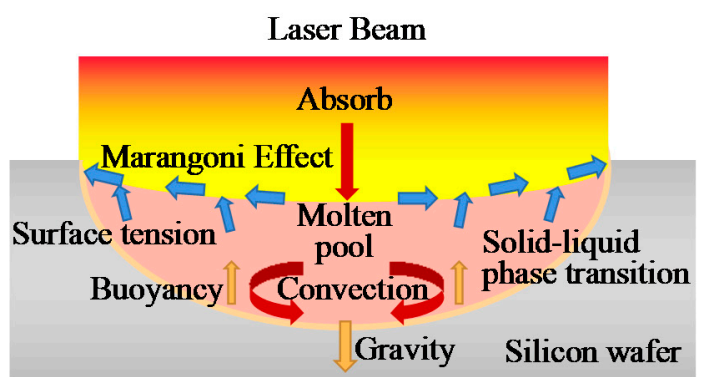

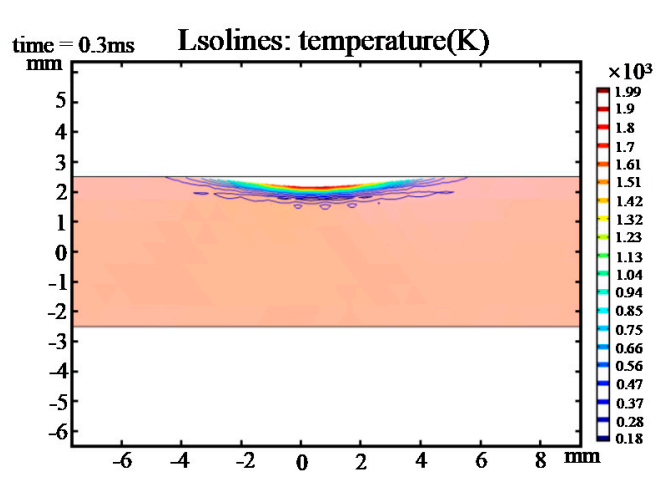

(c)

Figure 3. Schematic diagram of laser grinding mechanism: (a) laser directly removal of scratches and oxides, (b) laser melting, (c) temperature field simulation.

\subsection{Effect of Laser Grinding on Microstructure Evolution}

To investigate the microstructure change of single-crystal silicon wafer after laser grinding, the as-received surface and laser-grinded surface were exposed by SEM and EDS. As shown in Figure 4, the EDS face scanning analyses clearly revealed $\mathrm{Si}, \mathrm{C}$, and $\mathrm{O}$ are found in two surfaces. Si element are enriched and remain mostly homogeneous across the as-received surface and laser-grinded surface. However, the content of $\mathrm{C}$ and $\mathrm{O}$ in laser grinded surface reduced compared to the as-received surface. The decrease of $\mathrm{C}$ and $\mathrm{O}$ in laser-grinded surface results from oxide layer and pollutant disappearing by laser ablation.

XPS analysis was used to identify the chemical nature of the single-crystal silicon wafer surface before and after surface modification. XPS spectra obtained for as-received and laser-grinded surface are provided in Figure 5. XPS spectrum of both surfaces showed the presence of peaks corresponding to C1s, O1s, and Si2p. Figure 5a show the C1s spectra 
of the as-received and laser-grinded surface. A strong peak corresponding to the $\mathrm{C}-\mathrm{C}$ can be observed in C1s spectra of the as-received surface. However, the intensity of the C-C peak obviously decreased in $C 1$ s spectra of the laser-grinded surface. Other weaker peak $C=O$ was also found in the $\mathrm{C} 1 \mathrm{~s}$ spectra. The intensity of $\mathrm{C}=\mathrm{O}$ peak was stronger in $\mathrm{C} 1 \mathrm{~s}$ spectra of as-received surface than that in $\mathrm{C} 1 \mathrm{~s}$ spectra of laser-grinded surface. These results indicate that the oxide layer was sufficiently removed after laser grinding [21]. The conclusion can also be proved by $\mathrm{Si}-\mathrm{O}$ and $\mathrm{C}=\mathrm{O}$ peaks variation in O1s spectrum: the stronger $\mathrm{Si}-\mathrm{O}$ peak in single-crystal silicon original surface decreased after laser grinding (Figure $5 b$ ). Meanwhile, others peaks disappeared. It indicates that fewer or even no $\mathrm{C}=\mathrm{O}$ and $\mathrm{Si}-\mathrm{O}$ bonds were present on the laser-grinded surface and the disappeared oxide layer may be $\mathrm{SiO}_{2}$ [22]. The same conclusion can be concluded in Figure 5c. As shown in Figure 5c, peaks corresponding to $\mathrm{Si}-\mathrm{O}$ and $\mathrm{Si}$ were relatively strong on as-received surface compared to those of the laser-grinded surface in Si2p spectrum. The peak at $100 \mathrm{eV}$ is weaker after laser grinding, which indicates that the content of Si-C decreases after grinding. This is in good agreement with EDS results due to the reduction of $\mathrm{C}$ content. In addition, $\mathrm{SiO}_{2}$ peak disappeared from the laser-grinded surface. The result proved that the oxide layer is $\mathrm{SiO}_{2}[23,24]$.
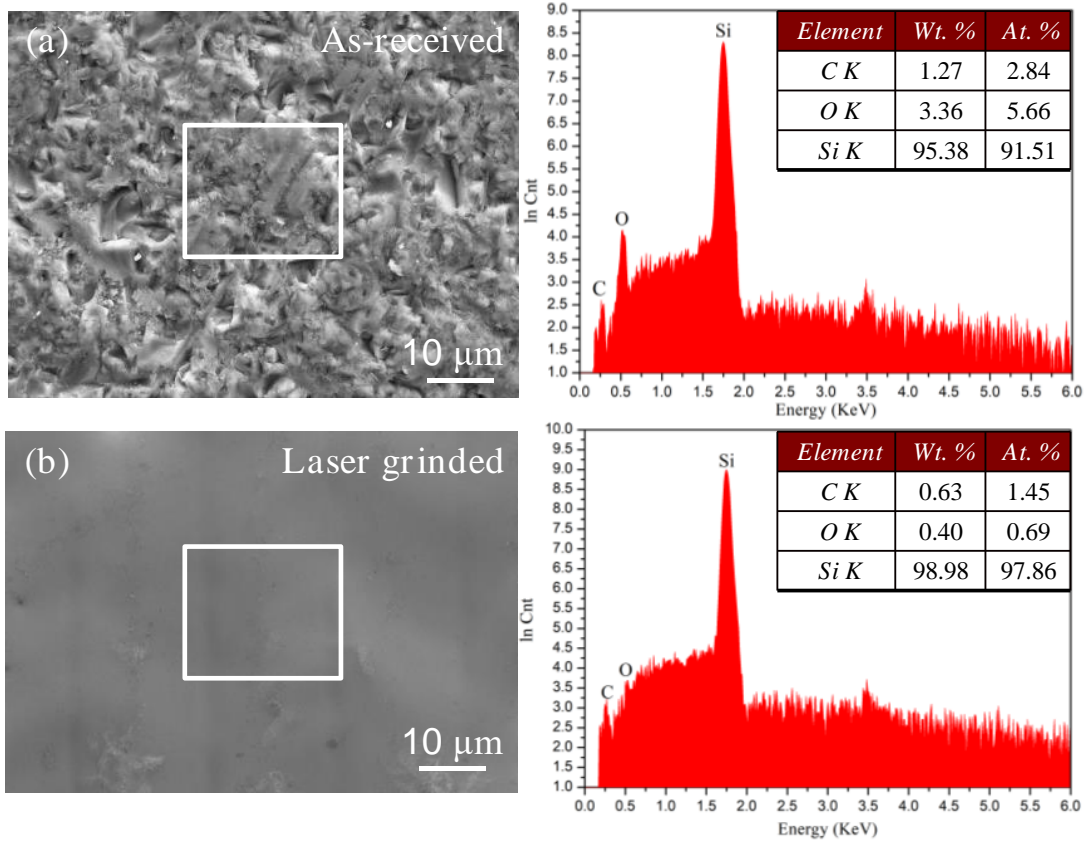

Figure 4. Elemental distribution and chemical composition (Wt. \%/At. \%) correspond to the white box in SEM from EDS spectrum analysis.
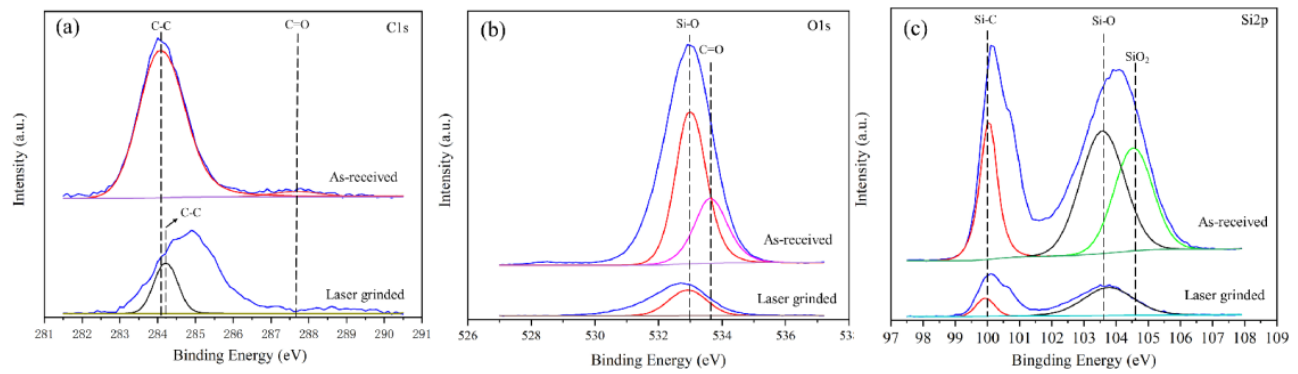

Figure 5. XPS spectra of the as-received and laser polished surface, which correspond to (a-c) result of curve fitting of C1s, O1s, and Si2p with bulk single crystal silicon surfaces (The XPS curves have been extracted from raw data after measurement and proceeded by standard analyses via Avantage software 5.967 (Thermo Fisher Scientific, Waltham, MA, USA)). 
The XRD patterns of as-received surface and laser-grinded surface of single-crystal silicon wafer samples are depicted in Figure 6a. As shown in Figure 6a, as-received surface and laser-grinded surface exhibit a sharp diffraction peak $\mathrm{Si}(400)$ at $2 \theta \approx 69.13^{\circ}$ indicating that $\mathrm{Si}$ is the matrix phase. Apart from the strong diffraction peaks corresponding to the Si matrix, two minor peaks appear at $2 \theta \approx 32.985^{\circ}$ and $61.75^{\circ}$ corresponding to the $\mathrm{SiO}_{2}$ (440) and $\mathrm{SiO}_{2}(-181)$ in the as-received surface, respectively. Obvious peak change can be observed after laser grinding. Only a minor peak at $2 \theta \approx 61.75^{\circ}$ existed in the laser-grinded surface and the peak intensity appreciably declined. It is reasonable to conclude that such a secondary phase still exists in the laser-grinded surface, although present in a very small volume fraction. Furthermore, no significant deviation in the peak position is observed in Figure 6a. As mentioned above, conclusions can be reached that the volume fraction of the $\mathrm{SiO}_{2}$ phase significantly decreased during the laser grinding process. This phenomenon is mainly attributed to the decrease in the oxygen content and no more oxygen can be injected into the silicon wafer during the laser-grinded process in Ar environment. This can be supported by the conclusion of EDS analysis.
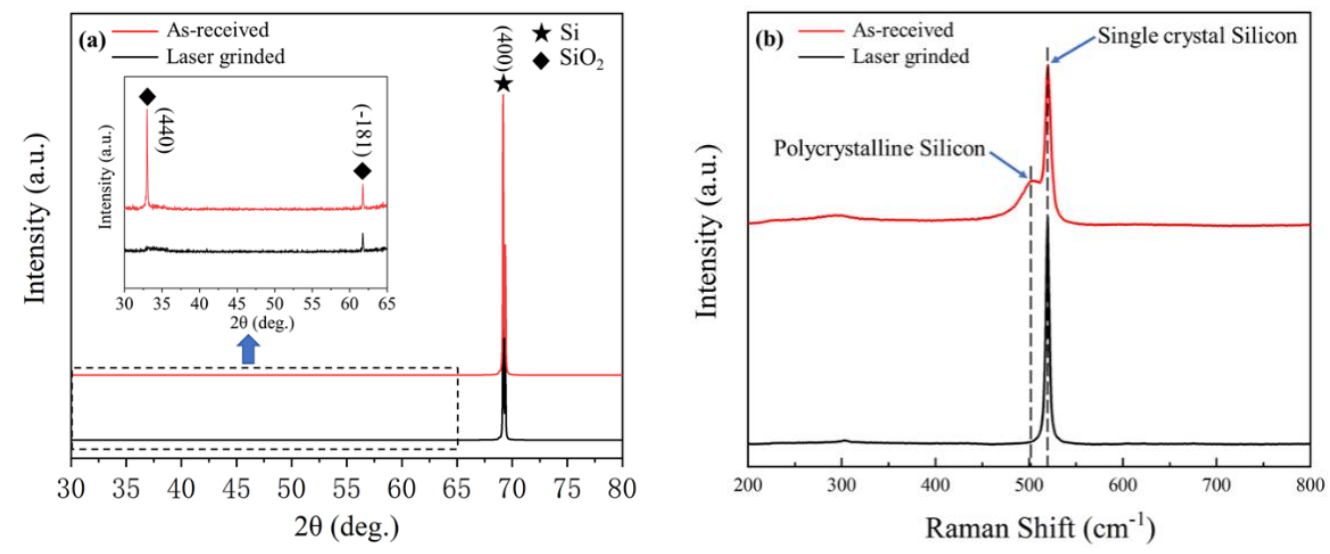

Figure 6. (a) XRD and (b) Raman spectrums from the laser-grinded surface and the as-received surface.

The crystallinity of the as-received surface and laser-grinded surface in single-crystal silicon were also investigated using Raman spectroscopy, as shown in Figure 6b. The asreceived surface and laser-grinded surface respectively showed a sharp peak at $520.29 \mathrm{~cm}^{-1}$ and $520.016 \mathrm{~cm}^{-1}$, which both are close to the bare single-crystal silicon (100) peak at $520 \mathrm{~cm}^{-1}$. Moreover, a minor peak was presented in the Raman spectroscopy of as-received surface. It is known that Raman spectra of the amorphous silicon, polycrystalline silicon, and single-crystal silicon are located around $480 \mathrm{~cm}^{-1}, 500-515 \mathrm{~cm}^{-1}$, and $520 \mathrm{~cm}^{-1}$, respectively [25]. Therefore, the minor peak represented polycrystalline silicon. The conclusion indicates that the polycrystalline silicon was completely transformed into single-crystal silicon during the laser-grinding process. Generally, conventional grinding will cause polycrystalline silicon layers $[4,11,13]$. After a laser pulse is irradiated on the surface, the polycrystalline silicon layers will be melted and becomes thicker and thicker when laser irradiation continues, reaching the whole polycrystalline silicon layers. Then after the laser pulse, cooling will result in bottom-up epitaxial regrowth from the singlecrystal silicon substrate. In this way, a perfect single-crystal structure can be obtained in the laser-irradiated surface [12].

\subsection{Effect of Laser Grinding on Resistivity}

Figure 7 shown the $I-V$ characteristic curve of as-receive and laser-grinded of singlecrystal silicon wafer. The current linearly increases with voltage increasing. The $I-V$ slope of laser-grinded is slightly smaller than that of as-received. 


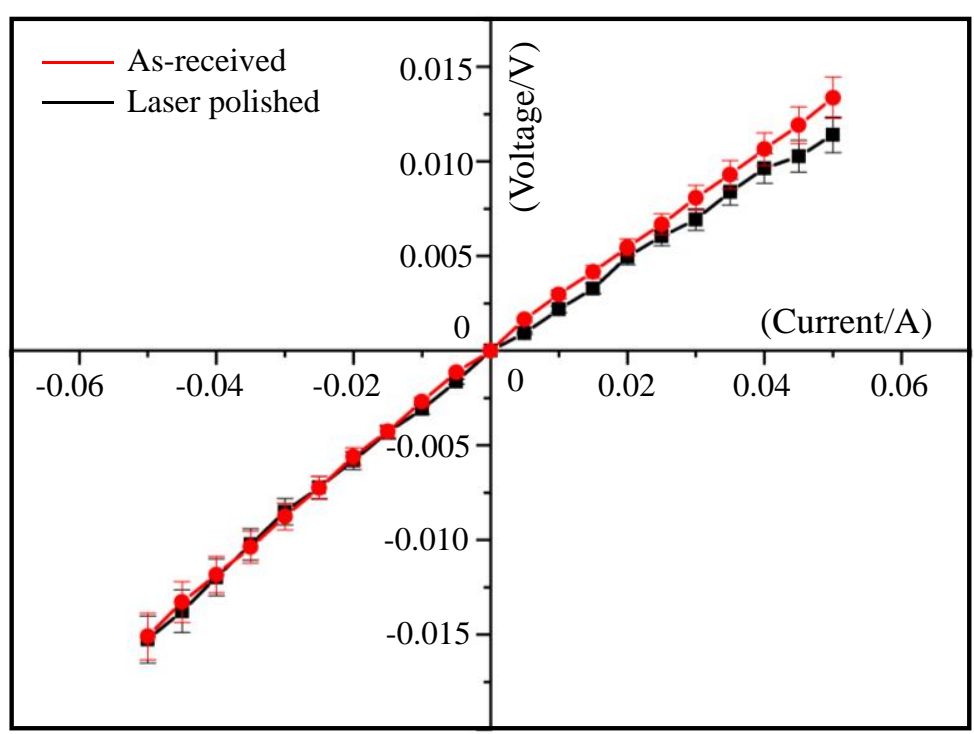

Figure 7. Comparison of $I-V$ characteristic curves of as-received and laser-grinded surfaces at the single-crystal silicon wafer.

The electrical resistivity of single-crystal silicon wafer was measured at room temperature by using four-probe test, and the resistivity was calculated via the following equation:

$$
\rho=\frac{R \times L}{S}
$$

where $\rho$ is the resistivity, $R$ is the resistance of silicon wafer sample, $S$ is the cross-sectional area of testing samples, and $L$ is the distance between the two electrodes.

The regression analysis of $I-V$ characteristic curve is used to estimate $R$ and $\rho$. The $R$ before and after laser grinding are estimated as $0.281 \Omega$ and $0.266 \Omega$, respectively, while $\rho$ is $0.572 \Omega \cdot \mathrm{cm}$ and $0.417 \Omega \cdot \mathrm{cm}$, respectively. The average value of the standardized residual error of these two regression models is 0 , and the deviation is 0.967 , which is close to 1 . It is proved that the $R$ and $\rho$ values obtained by using the $I-V$ characteristic curve are unbiased.

Table 1 lists the resistivity of silicon wafer with as-received and laser-grinded. Compared with the resistivity of as-received silicon wafer, the resistivity of laser-grinded silicon wafer was smaller. The decrease of the resistivity is attributed to the disappeared polycrystalline silicon, as shown in Figure $4 \mathrm{~b}$. Therefore, the laser grinding process can reduce the resistivity of silicon wafer.

Table 1. The resistivity of single-crystal silicon wafer samples with as-received and laser-grinded.

\begin{tabular}{ccc}
\hline Specimen & As-Received & Laser-Grinded \\
\hline Resistivity $(\Omega \cdot \mathrm{cm})$ & 0.572 & 0.417 \\
\hline
\end{tabular}

\section{Conclusions}

In this study, surface quality, microstructure, and resistivity of single-crystal silicon wafer before and after laser grinding were analyzed. The following conclusions can be drawn:

1. Laser grinding reduced the surface roughness of single-crystal silicon wafer by over $81 \%$, when measured at the mm scale, but achieved a roughness level of only $\mathrm{Ra}=75 \mathrm{~nm}$ when measured at the micro-scale. Meanwhile, the laser-grinded surface changes were smother because laser grinding removes abundant peaks.

2. Laser grinding could decline oxygen content of the single-crystal silicon wafer. EDS and XPS analysis results proved this conclusion. XRD analysis showed that the 
$\mathrm{SiO}_{2}$ phase disappeared after laser grinding. It indicated that the oxide layer was completely removed during the laser-grinding processing.

3. Raman spectra of as-received surface and laser-grinded surface analysis showed that crystallinity in the grinded region were changed after laser grinding. Polycrystalline $\mathrm{Si}$ was transformed into the single- crystal structure during laser grinding.

4. Laser grinding could reduce resistivity of single-crystal silicon wafer due to disappeared polycrystalline silicon, but the effect is not obvious.

Author Contributions: Conceptualization, Y.G.; data curation, X.L.; formal analysis, Y.W.; funding acquisition, Y.G.; investigation, X.L.; resources, Y.G.; supervision, Y.G.; validation, Y.W.; visualization, X.L.; writing-review and editing, Y.W. and X.L. All authors have read and agreed to the published version of the manuscript.

Funding: This research was founded by the National Key Research and Development Program of China, grant number 2018YFB1107700.

Institutional Review Board Statement: Not applicable.

Informed Consent Statement: Not applicable.

Conflicts of Interest: The authors declare no conflict of interest.

\section{References}

1. Pei, Z.; Alan, S. Fine grinding of silicon wafers. Int. J. Mach. Tools Manuf. 2001, 5, 659-672. [CrossRef]

2. Pei, Z.; Kassir, S.; Bhagavat, M.; Fisher, G.R. An experimental investigation into soft-pad grinding of wire-sawn silicon wafers. Int. J. Mach. Tools Manuf. 2004, 44, 299-306. [CrossRef]

3. Li, Z.; Pei, Z.; Fisher, G.R. Simultaneous double side grinding of silicon wafers: A literature review. Int. J. Mach. Tools Manuf. 2006, 46, 1449-1458. [CrossRef]

4. Yan, J.; Sakai, S.; Isogai, H.; Izunome, K. Recovery of microstructure and surface topography of grinding-damaged silicon wafers by nanosecond-pulsed laser irradiation. Semicond. Sci. Technol. 2009, 24, 105018. [CrossRef]

5. Li, H.; Yu, T.; Zhu, L.; Wang, W.S. Analytical modeling of grinding-induced subsurface damage in monocrystalline silicon. Mater. Des. 2017, 130, 250-262. [CrossRef]

6. Yin, J.; Bai, Q.; Li, Y.; Zhang, B. Formation of subsurface cracks in silicon wafers by grinding. Nanotechnol. Precis. Eng. 2018, 1, 172-179. [CrossRef]

7. Deschaines, T.; Hodkiewicz, J.; Henson, P. Characterization of Amorphous and Microcrystalline Silicon Using Raman Spectroscopy; Thermo Fischer Scientific: Madison, WI, USA, 2009.

8. Pei, Z.; Fisher, G.R.; Liu, J. Grinding of silicon wafers: A review from historical perspectives. Int. J. Mach. Tools Manuf. 2008, 48, 1297-1307. [CrossRef]

9. Zhang, F.; Levine, L.E.; Allen, A.J.; Stoudt, M.R.; Lindwall, G.; Lass, E.A.; Williams, M.E.; Idell, Y.; Campbell, C.E. Effect of heat treatment on the microstructural evolution of a nickel-based superalloy additive-manufactured by laser powder bed fusion. Acta Mater. 2018, 152, 200-214. [CrossRef] [PubMed]

10. Bhaduri, D.; Penchev, P.; Batal, A.; Dimov, S.; Soo, S.L.; Sten, S.; Harrysson, U.; Zhang, Z.; Dong, H. Laser polishing of 3D printed mesoscale components. Appl. Surf. Sci. 2017, 405, 29-46. [CrossRef]

11. Yan, J.; Asami, T.; Kuriyagawa, T. Response of machining-damaged single-crystalline silicon wafers to nanosecond pulsed laser irradiation. Semicond. Sci. Technol. 2007, 22, 392-395. [CrossRef]

12. Niitsu, K.; Tayama, Y.; Kato, T.; Maehara, H.; Yan, J. Characterization of recrystallized depth and dopant distribution in laser recovery of grinding damage in single-crystal silicon. Mater. Sci. Semicond. Process. 2018, 82, 54-61. [CrossRef]

13. Yan, J.; Muto, S.Y.; Kuriyagawa, T. Processing grinding-damaged silicon wafers by high-frequency nano-second laser irradiation. Adv. Mater. Res. 2009, 76-78, 451-456. [CrossRef]

14. Sun, Z.; Gupta, M.C. Laser processing of silicon for photovoltaics and structural phase transformation. Appl. Surf. Sci. 2018, 456, 342-350. [CrossRef]

15. Mahdieh, M.H.; Sobhani, M. Experimental study of nano-structure and optical properties of polished silicon irradiated by nanosecond Nd:YAG laser beam. J. Instrum. 2012, 7, C01076. [CrossRef]

16. Wang, X.; Zheng, H.; Tan, C.; Wang, F.; Yu, H.Y.; Pey, K.L. Femtosecond laser induced surface nanostructuring and simulataneous crystallization of amorphous thin silicon film. Opt. Express 2010, 18, 19379-19385. [CrossRef] [PubMed]

17. Farrokhi, H.; Zhou, W.; Zheng, H.; Li, Z.L. Non-ablative texturing of silicon surface with a continuous wave fiber laser. Opt. Express 2012, 20, 23180. [CrossRef] [PubMed]

18. Jiao, L.; Moon, S.K.; Ng, E.Y.K.; Zheng, H.Y.; Son, H.S. Influence of substrate heating on hole geometry and spatter area in femtosecond laser drilling of silicon. Appl. Phys. Lett. 2014, 104, 181902. [CrossRef] 
19. Pleasants, S.; Kane, D.M. Laser cleaning of aluminum particles on glass and silica substrates:Experiment and quasistatic model. Appl. Phys. 2003, 93, 8862-8866. [CrossRef]

20. Li, K.; Zhao, Z.; Zhou, H.; Zhou, H.; Jin, J. Numerical analyses of molten pool evolution in laser polishing Ti6Al4V. J. Manuf. Process. 2020, 58, 574-584. [CrossRef]

21. Deng, H.; Endo, K.; Yamamura, K. Competition between surface modification and abrasive polishing: A method of controlling the surface atomic structure of $4 \mathrm{H}-\mathrm{SiC}$ (0001). Sci. Rep. 2015, 5, 8947. [CrossRef]

22. Chen, G.; Li, J.; Long, J.; Luo, H.; Zhou, Y.; Xie, X.; Pan, G. Surface modulation to enhance chemical mechanical polishing performance of sliced silicon carbide Si-face. Appl. Surf. Sci. 2021, 536, 147963. [CrossRef]

23. Yang, X.; Yang, X.; Kawai, K.; Arima, K.; Yamamura, K. Highly efficient planarization of sliced 4H-SiC (0001) wafer by slurryless electrochemical mechanical polishing. Int. J. Mach. Tools Manuf. 2019, 144, 103431. [CrossRef]

24. Yamamura, K.; Takiguchi, T.; Ueda, M.; Deng, H.; Hattori, A.; Zettsu, N. Plasma assisted polishing of single crystal SiC for obtaining atomically flat strain-free surface. CIRP Ann. 2011, 60, 571-574. [CrossRef]

25. Nast, O.; Wenham, S.R. Elucidation of the layer exchange mechanism in the formation of polycrystalline silicon by aluminuminduced crystallization. J. Appl. Phys. 2000, 88, 124-132. [CrossRef] 